\title{
On the potential of gassy marine soils triggering submarine slope instabilities
}

\author{
Pauline Kaminski ${ }^{1,}{ }^{*}$ and Jürgen Grabe ${ }^{1}$ \\ ${ }^{1}$ Hamburg University of Technology, Institute of Geotechnical Engineering and Construction Management, Harburger \\ Schlossstrasse 20, 21079 Hamburg, Germany
}

\begin{abstract}
The development of debris flows and turbidity currents in the course of a submarine slope failure event can cause major damage in offshore infrastructure. Additionally, the tsunamogenic potential of large slope failures at continental margins poses a direct threat to coastal communities. Therefore, the trigger mechanisms of submarine slope failures have been thoroughly investigated in the past. However, the influence of free gas in the sediment, which has been observed close to several slide events, remains unexplained. In order to evaluate the potential of gassy marine soils to precondition or trigger slope failure the mechanical behaviour of gassy soils is assessed based on an extensive literature review. It is found that gas-induced excess pore pressures can lead to liquefaction failure in sands, while cohesive, gassy soils show a less conclusive response. Hence, fine-grained soils and approaches to implement the gas impact into relevant existing constitutive soil models are assessed in greater detail. Concludingly, based on the predominant boundary conditions in failure prone regions at the continental margins, free gas occurrence can be defined as a preconditioning factor rather than as a definite trigger mechanism.
\end{abstract}

\section{Introduction}

The exploitation of energetic resources in the offshore areas has been successfully conducted in the past years, forwarding into deeper waters in the recent years. Leaving the shelf seas and approaching the continental slopes stability assessments of the latter become relevant [1]. Submarine slope failures on the continental slopes are known to be magnitudes larger than failure events onshore and happen on very gentle slopes: up to hundreds of $\mathrm{km}^{3}$ slide mass failed on slopes of around $1^{\circ}$ [2-4]. The trigger mechanisms of these slide events have not been conclusively clarified. However, the occurrence of marine gases has been linked to several investigated slide events $[5,6]$. The respective boundary conditions regarding water depths, gas amounts, loading conditions, and soil characteristics vary widely. Nevertheless, in nearly all circumstances free gas in the soil is strongly suspected to have a negative influence on the slope's bearing capacity. Here, possible approaches to assess the hazardous potential of marine gassy sediments are given. These include theoretical models of geomechanical processes in gassy soil. Furthermore, approaches to include the gas phase, or rather the gases impact, in constitutive models in order to make a numerical assessment of gassy soils possible are discussed. The current state of knowledge does not allow an extensive analysis of gassy soils. Nevertheless, it becomes clear that gas occurrence alone is not very likely to trigger a failure. However, the impact of a free gas phase on the overall stability of a slope requires further consideration in combination with other weakening factors.

\section{Submarine landslides and gas occurrence}

The exact boundary conditions that must be met to trigger a major landslide have been intensively investigated and discussed in recent years finding that some marine areas are more prone to landslides than others. These include, for example, the submarine deltas or fans of large rivers. In these regions, high sedimentation rates lead to a build-up in excess pore pressures or an oversteepening of the slopes, which will consequently lead to a loss of stability. Seismic activity is also considered one of the most common trigger mechanisms for submarine slides. However, many large landslides have also been detected at continental margins where low sedimentation rates prevail and earthquakes are not a common feature [7]. Furthermore, earthquakes of any kind of magnitude do not necessarily cause landslides. Rather, many large landslides occur in regions with little seismic activity. It is therefore concluded that earthquakes may initiate landslides, but are not the only acting trigger mechanism. Additionally, hydrate dissociation was excluded from consideration as a generally applicable mechanism as for several larger slides the found headwalls are situated well below the gas hydrate stability zone $[8,9]$. Free gas and migration processes have thus been suspected to weaken the soil

\footnotetext{
* Corresponding author: pauline.kaminski@tuhh.de
} 
and support instability of slopes $[8,10,11]$. The currently investigated hypotheses involve free gas in a soil generating high excess pore pressures leading to liquefaction, or a gas-induced decrease in shearing resistance causing slope instability. Thereby, the marine gases could be generated by bacterial metabolic processes in shallow soil layers or occur in deeper soil layers where thermogenic processes predominate. Depending on the local boundary conditions the gas volume, pressure, flux, and chemical composition varies [12]. Moreover, the characteristics and properties of the gas phase within the soil strongly depend on the characteristic features of the prevailing soil.

The headwalls left from a great number of past landslides are found in water depths of $1,000-1,300 \mathrm{~m}$ [13]. Generally speaking, due to the transportation processes one can assume that the sediments in these regions are dominated by silts and clays. The precise identification of soil types responsible for the slope instabilities is, however, somewhat difficult, as the slide incidents are usually detected and examined when the slide has already happened. From the investigation of the slide deposits the responsible layer cannot be identified reliably, as it is unclear whether it was involved in the sliding process or remained in its original position [13]. Nevertheless, the assumption of predominating finegrained sediments is consistent with several geotechnical soil analyses reported in the literature. The deposition process of fine particles leads to a very loose packing and a well-stratified seabed. Consequently, marine sediments usually show high water contents and plasticities and a quite sensitive reaction to disturbance. These features usually come along with high compressibilities and a low shear strength. The investigations by, for example, [14-18] confirm this assumed soil behaviour. Extremely high water contents exceeding the liquid limits and a highly plastic behaviour were noteworthy. Thus, a very low shearing resistance can be expected as soils with water contents at their liquid limit exhibit by definition an undrained shear strength of $1.7 \mathrm{kPa}$. Additionally, a very high sensitivity in deep sea sediments which is comparable to quick clay was documented. Depending on the sedimentation rates, erosion processes, and former geological developments the soil conditions and the consolidation history of a soil can vary strongly. Thus, for detailed information the local conditions at a specific slide event need to be assessed.

\section{Gassy soil mechanics}

Soils that are neither fully saturated nor dry are called unsaturated. Usually, the term unsaturated soils is associated with a low degree of saturation, like it would appear in the top soil on land, showing a discontinuous water phase and a continuous gas phase in the pore spaces [19]. The surface tension of the water leads to the formation of menisci, bridging the pore spaces between the grains and ultimately applying capillary suction pressure. In contrast, the term gassy soils usually refers to an unsaturated state with a high degree of saturation, and hence a continuous water phase and a discontinuous gas phase. The gas will be present in bubble form within the pore space without meniscular contact to the solids, or as differently shaped large voids within the soil matrix, depending on the specific boundary conditions [20]. Due to the high water content capillary effects do not influence the mechanical behaviour. It is a common assumption for gassy soils that, due to the magnitude of the pore size or pore pressure, the interfacial tension between the gas and the liquid phase is insignificant and can be ignored [21]. Instead, other properties characterise the mechanical reaction to different states of loading [22]. As gassy soils are a common phenomenon in the marine environment, the gas often consists of methane and is exposed to pressures well above the atmospheric pressure [23]. Most investigations on gassy sediments have focused on a saturation of in average $>85 \%-90 \%[22,24-26]$.

In fine-grained sediments the pore spaces are very small. Therefore, high gas pressures are needed to displace the pore water from the capillary tube in between two grains. Because the necessary gas pressures usually exceed the strength of the soil, the gas pressure will lead to small fractures in the fully saturated soil. Thereby, the gas forms voids surrounded by a saturated soil matrix instead of invading the pore space - as generally known from coarse unsaturated soils. The voids' diameter is several orders of magnitude larger than the average particle diameter [27]. A distinct conclusion that can be drawn from this appearance of gassy soil is a clear separation of the pore spaces occupied by the water and gas phase. [20] introduced the parameters $e_{\mathrm{m}}$, the void ratio of the saturated soil matrix, and $f$, the volume fraction of bubbles, in order to meet this observation. $e_{\mathrm{m}}$ describes the pore space in the fully saturated soil matrix occupied by water and $f$ describes the relative volume of the soil which is gas-filled. Both parameters depend on the degree of saturation $S_{\mathrm{r}}$ and the generally applicable void ratio $e$ :

$$
\begin{gathered}
e_{\mathrm{m}}=S_{\mathrm{r}} * e \\
f=\left(1-S_{\mathrm{r}}\right) * e /(1+e)
\end{gathered}
$$

Due to the void formation the local stress state in the soil matrix around the gas cavity is altered. Stress concentrations in the surrounding material are induced by the gas bubble pressure. The normal stress in the saturated soil matrix around the gas void equals the gas pressure $u_{\mathrm{g}}$. If the soil is deformed, the stress state in vicinity of the bubbles adjusts according to the pressure in the bubble. Additionally, the global total stress acts on the soil. The combination of the two stresses results in a field of pore water pressures that differs throughout the soil. The dissipation of pore pressure peaks leads to localised consolidation processes and possibly to soil deformation. At the interface of the gas and the saturated soil matrix the pore water forms menisci bridging the spaces between the solid particles. The radius of the menisci does not equal the radius of the gas void and the gas and the pore water pressures are not inevitably equal. For a high pressure within the void an intrusion of gas to 
the pore space will occur until the required capillary pressure becomes too high. On the opposite, if the gas pressure in the voids is low, water will invade the cavity until the radius of the meniscus equals the cavity radius. If the gas pressure drops further, the bubble is flooded. Depending on the unique position of the single soil particles, every meniscus will adjust independently. This leads to the conclusion that the internal gas pressure in the void does not correlate directly with the void shape, size, the curvature of the menisci, and the surface tension. Consequently, the description of the void shape is very difficult. Therefore, in the following all voids are assumed to be spherical and the surface tension of the water, which acts at every meniscus, is neglected assuming the capillary pressure to be an independent variable evoked by the gas-water pressure difference, which does not influence the overall soil behaviour $[20,23,28]$. Figure 1 shows the features of fine-grained, gassy soils and the respective idealization.
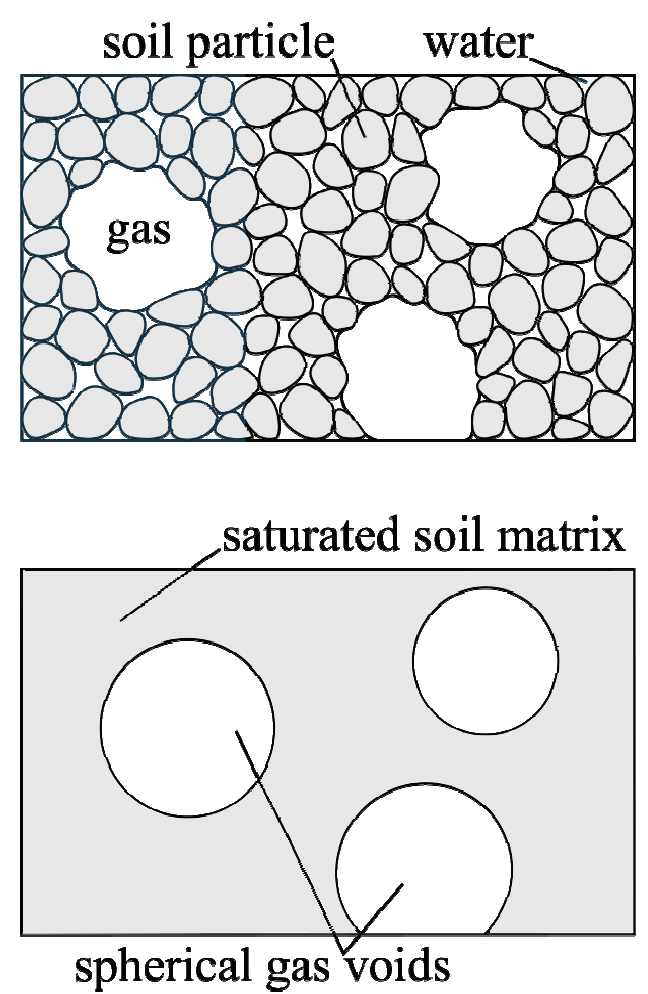

Fig. 1. Structure of gassy soil and the according continuum model [20]

The voids are randomly distributed within the soil matrix. Based on the described restrictive capillary pressure the gas phase is unable to move freely within the soil. Hence, the voids are fixed with respect to the soil structure, i.e. the gas voids do not move with the pore water. Assuming a state without complete soil fracturing, gas flow between different voids can only take place in a dissolved state by either advection or diffusion. By diffusive processes, pressure gradients between neighbouring gas cavities can be equalised. This influences the gas pressure in the voids and thus possibly prevents or induces bubble flooding or local consolidation processes. The time-dependent processes of gassy soils involve local consolidation around the gas cavities (a matter of seconds), dis- and exsolution processes of gas (a matter of minutes to hours) and global consolidation of the saturated soil matrix, if drainage is allowed (which can take days, weeks or years, depending on the problem at hand). This makes the description of the deformation behaviour of gassy soils a rather complex issue [20,23,28].

Moreover, from the described soil behaviour it becomes obvious that it is difficult to define an effective stress relationship for the complete soil [28]. With the legitimate neglection of capillary suction pressures, models for unsaturated soils, e.g. Bishop's model, do not provide a valid description of effective stresses in finegrained soil with large gas inclusions. The soil matrix in a gassy fine-grained soil reacts independently with respect to the gas voids. Under compressive loading the characteristic response of the saturated soil matrix is similar to a fully saturated soil. The behaviour of the gas voids relates to the total stress state [29]. To meet this fact, the parameter of operative stress $\sigma$ " was introduced [28]. It solely describes the saturated soil matrix and leaves out the stresses at the gas inclusions. The effective stress $\sigma^{\prime}$ is generally defined by

$$
\sigma^{\prime}=\sigma-u
$$

$u$ describing the pore water pressure and $\sigma$ the total stress. The operative stress $\sigma$ ' ' is defined by

$$
\sigma^{\prime \prime}=\sigma-u_{\mathrm{w}} .
$$

The operative stress offers a first approach to describing the complex stress state in a gassy soil. A complete description is, however, still pending.

Several experimental studies have been conducted to quantify the effect of enclosed gas bubbles on the mechanical behaviour of soils. The natural consolidation processes under gravity loading were investigated by [30] and it was found that low gas contents prevent a complete consolidation. As mentioned above, the saturated soil matrix and the gas voids show independent answers to compressive loading. The corresponding consolidation behaviour is described by the double compressibility model developed by [29] which defines two separate mechanisms: an undrained response under total stress changes and a drained response under changes in the consolidation pressure. The preconsolidation pressure of a gassy soil decreases with increasing gas content. The compressibility of a gassy soil generally exceed that of its saturated equivalent. Gas volume expansion generally leads to decreasing effective stresses or excess pore pressure generation, respectively. Between the removal of load and changes in the gas regime a time difference occurs. The reasons for the temporal offset are not understood, yet [27].

The findings on the shearing resistance have been ambiguous. This results partly from the different procedures, soils, and gases that were applied. The work of [31] shows that the structural damage caused by gas leads to a reduction in shear strength when the soil is in a subsequent and fully saturated state (see fig. 2). As the 
amount of gas influences the degree auf damage, a higher gas content will lead to a higher decrease in strength. According to [20], the shearing resistance of a soil in a not fully saturated state depends on the applied pressure conditions, because these parameters influence processes like bubble shrinkage and flooding. These processes as well as gas diffusion could be identified but their influence on the shearing resistance could not be quantified. It is hence difficult to conclude a definite statement regarding the influence on the shear strength based on the current state of knowledge.

\section{Constitutive modelling}

Based on the theoretical model for the mechanical processes in fine-grained, gassy soils [32] developed an analytical description for the upper and lower boundaries of the shear strength. Advancing this first approach, several publications use the Cam Clay Model as a basis to describe the stress-strain behaviour of gassy finegrained soils. The Cam Clay Model is a basic elastoplastic model which is well-established for the description of soft, cohesive soils. The four typical features of the model include isotropic elasticity, an elliptic yield surface in the principle stress space which passes through the origin and thus does not cover tensile stress states, normality, and a hardening rule that directly depends on the normal compression of the soil [33].

A valid approach was published by [34] based on the experiments introduced by [31]. The implemented results are hence based on a fully re-saturated soil during the shearing phase. The presented model is an extended Cam Clay model that contains several adaptations to account for the effects of gas bubbles in the saturated soil matrix. It was chosen to apply the following assumptions: the effective stress and saturation of the pore water are reduced due to gas bubble growth following undrained loading, the increase in compressibility and the decrease in pre-consolidation pressure and shear strength due to the damage caused by bubble growth, and potential discontinuities in the effective stress paths due to subsequently saturated voids collapsing under loading. For their implementation the undrained unloading formulation by [21] including a damaged swelling coefficient was applied allowing the depiction of discontinuities in the normal consolidation line during reloading. The chosen yield curve depends on the pre-consolidation pressure, which is likewise a function of the saturation dependent damage factor. Focusing on the detrimental effect of the gas phase during an unloading-reloading cycle, the hardening law includes a gas cavity growth induced shrinkage of the yield curve.

[35] present a further method which is based on a composite material approach. The experimental results presented by [36] provide the framework for this study. Here, the modified Cam Clay model is used to describe the stress-strain behaviour of only the fully saturated soil matrix. Hence, the elastic parameters are expressed as a function of $e_{\mathrm{m}}$ instead of $e$. The presence of a free gas phase is solely implied in the hardening rule. This approach depicts the processes of bubble flooding and shrinkage brought into the discussion by [19] by including them the mathematical description of plastic hardening. Bubble flooding and shrinkage are controlled by the relation of gas pressure and the pressure in the pore water of the surrounding soil matrix. Thus, an estimate of the initial gas pressure in the voids is made based on the expressions for upper and lower bounds introduced by [19]. The further development of the gas pressure is described by the volumetric behaviour of the gas phase, which is characterised by Boyle's law.

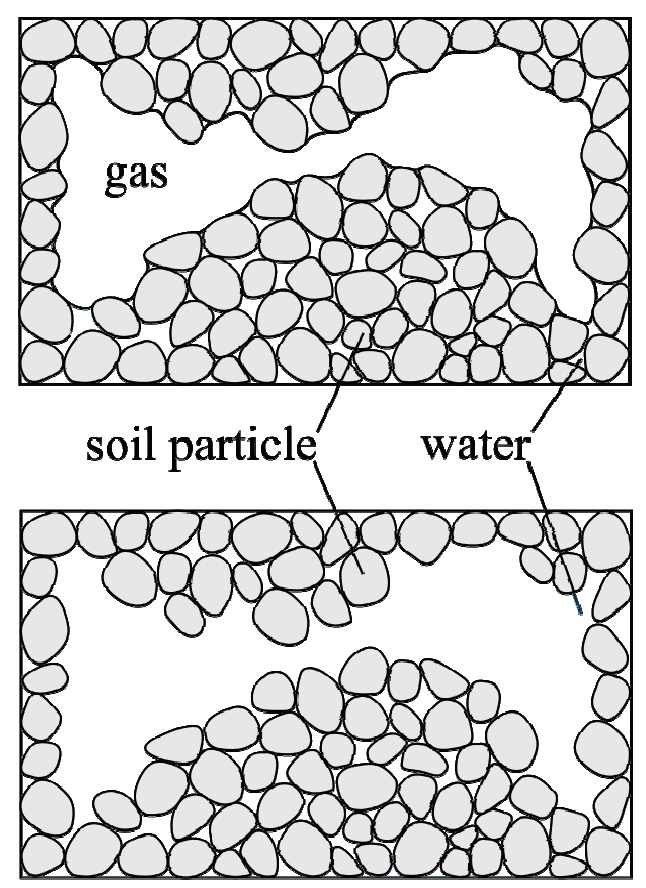

Fig. 2. Basic assumption of the soil characteristics before and after reloading following the gas described by $[30,32]$

Both approaches were verified by modelling several loading states of experiments reported in the relevant literature and showed good agreement. The quintessence of the comparison between [34] and the analytic [32]model as well as [35] is that the latter display the stage immediately after bubble formation, i.e. the gassy soil, while [34] describe stress paths with a full resolution, i.e. the disturbed soil due to former gas exsolution.

For a detailed derivation of the governing equations of the presented models the reader is referred to [34] and [35] and references therein. A variety of further approaches using the Cam Clay model include the description of unsaturated soil with the van Genuchten approach which is based on the generation of suction due to capillary forces. As the experimental results clearly show fundamentally different characteristics in finegrained soils with gas contents of below $15 \%$ these models, however, do not provide an accurate description. 


\section{Conclusion}

Based on the general characteristics of submarine slopes elaborated above, it becomes clear that traditional slope stability analyses are rather unsuccessful in investigating the problem at hand. With slopes of around $1^{\circ}$ the friction alone would prevent failure in any onshore soil for a variety of imaginable settings. However, it can be assumed on the basis of the researched soil properties in the deep sea area that a fundamental change of the soil characteristics, like extensive liquefaction, occurs in the very sensitive soils due to processes that are not yet understood. The cause of these processes could be the occurrence of free gas. The understanding of soil mechanics in the field of gassy soils is not yet very advanced. Nevertheless, the current status of knowledge allows the hypothesis of a predominantly negative impact even if the experimental results are equivocal.

Moreover, it can be established that two different approaches are being followed. On the one hand, soil disturbed by gas is examined, which is in a state of complete saturation at the time of load application. On the other hand, soils are examined which contain a third phase, specifically free gas in inclusions, at the time of load application. These two approaches are also found in the existing attempts of introducing the findings from laboratory experiments in numerical modelling by adapting well-established constitutive models. Due to the lack of in-situ observations of the gas phase characteristics it is rather difficult to assess the degree of accuracy of the approaches. Additionally, for both approaches the number of experimental results is limited. In order to forward the understanding of the in-situ processes and to advance the precision of the constitutive material descriptions further investigations are required.

This work is part of a DFG-funded (GR 1024/35-1), cooperative research project at Hamburg University of Technology and GEOMAR Helmholtz Centre for Ocean Research.

\section{References}

1. E. T. Dean, Offshore geotechnical engineering: Principles and practice (2010)

2. J. Locat, H. Lee, Submarine landslides: Advances and challenges. Can. Geotech. J. 39.1, pp. 193-212 (2002)

3. D. G. Masson, C. B. Harbitz, R. B.Wynn, G. Pedersen, F. Løvholt, Submarine Landslides: Processes, Triggers and Hazard Prediction. Phil. Trans.: Math., Phys. Eng. Sc. 364.1845, pp. 20092039 (2006)

4. M. Vanneste, N. Sultan, S. Garziglia, C. F. Forsberg, J.-S. L'Heureux, Seafloor instabilities and sediment deformation processes: The need for integrated, multi-disciplinary investigantions. Mar. Geol. 352.C, pp. 183-214 (2014)

5. S. Lafuerza, N. Sultan, M. Canals, G. Lastras, A. Cattaneo, J. Frigola, S. Costa, C. Berndt, Failure mechnisms of Ana Slide from geotechnical evidence,
Eivissa Channel, Western Mediterranean Sea. Mar. Geol. 307-310, pp. 1-21 (2012)

6. J. Elger, C. Berndt, S. Krastel, D. J. Piper, F. Gross, R. F. Spielhagen, S. Meyer, The Fram Slide off Svalbard: a submarine landslide on a lowsedimentation-rate glacial continental margin. J. Geol. Soc. 172.2, pp. 153-156 (2015)

7. M. Urlaub, P. J. Talling, A. Zervos, D. Masson, What causes large submarine landslides on low gradient $\left(<2^{\circ}\right)$ continental slopes with slow $(\sim 0.15 \mathrm{~m} / \mathrm{kyr})$ sediment accumulation?. J. Geophys. Res. Sol. Earth 120.10, pp. 6722-6739 (2015)

8. M. J. Hornbach, L. L. Lavier, C. D. Ruppel, Triggering mechanism and tsunamogenic potential of the Cape Fear Slide complex, US Atlantic margin. Geochem. Geophys. Geosys. 8.12 (2007)

9. M. Urlaub, A. Zervos, P. J. Talling, D. G. Masson, C. I. Clayton, Submarine Mass Movements and Their Consequences pp. 277-287 (2012)

10. H. Lee, J. Baraza, Geotechnical characteristics and slope stability in the Gulf of Cadiz. Mar. Geol. 155.1, pp. 173-190 (1999)

11. J. Elger, C. Berndt, L. Rüpke, S. Krastel, F. Gross, W. Geissler, Submarine slope failures due to pipe structure formation. Nat. Com. 9.1, pp. 1-6. (2018)

12. D. Archer, Methane hydrate stability and anthropogenic climate change. Biogeosciences $\mathbf{4}$, pp. 521-544 (2007)

13. H. Haflidason, H. P. Sejrup, A. Nygård, J. Mienert, P. Bryn, R. Lien, C. F. Forsberg, K. Berg, D. Masson, The Storegga Slide: architecture, geometry and slide development. Mar. Geol. 213.1-4, pp. 201234 (2004)

14. B. A. Baudet, E. W. Ho, On the behaviour of deepocean sediments. Géotechnique 54.9, pp. 571-580 (2004)

15. H. G. Brandes, Geotechnical characteristics of deep-sea sediments from the North Atlantic and North Pacific oceans. Ocean Eng. 38.7, pp. 835-848 (2011)

16. C. Lee, T. S. Yun, J.-S. Lee, J. J. Bahk, J. C. Santamarina, Geotechnical characterization of marine sediments in the Ulleung Basin, East Sea. Eng. Geol. 117.1-2, pp. 151-158 (2011)

17. H. Daigle, B. Dugan, Data Report: Permeability, consolidation, stress state, and pore system characteristics of sediments from sites C0011, C0012, and C0018 of the Nakai Trough. Proc. IODP 333.2 (2014)

18. B. N. Madhusudhan, M. A. Clare, C. R. Clayton, J. E. Hunt, Geotechnical profiling of deep-ocean sediments at the AFEN submarine slide complex. Quart. J. Eng. Geol. Hydrogeo. 50.2, pp. 148-157 (2017)

19. D. G. Fredlund, H. Rahardjo, M. D. Fredlund, Unsaturated Soil Mechanics in Engineering Practice (2012) 
20. S. J. Wheeler, The stress-strain behaviour of soils containing gas bubbles. $\mathrm{PhD}$ Thesis, Univ. Oxford (1986)

21. J. C. Sobkowicz, N. R. Morgenstern, The undrained equilibrium behaviour of gassy sediments. Can. Geotech. J. 21.3, pp. 439-448 (1984)

22. S. Nageswaran, Effect of gas bubbles on the sea bed behaviour. PhD Thesis, St. Catherine's Col. Oxford (1983)

23. G. C. Sills, S. J. Wheeler, The significance of gas for offshore operations. Cont. Shelf Res. 12.10, pp. 1239-1250 (1992)

24. J. Grozic, P. Robertson, N. Morgenstern, The behaviour of loose gassy sand. Can. Geotech. J. 36.3, pp. 482-492 (1999)

25. J. Grozic, L., F. Nadim, T. J. Kvalstad, On the undrained shear strength of gassy clays. Comp. Geotech. 32.7, pp. 483-490 (2005)

26. Y. Wang, L. Kong, Y. Wang, M. Wang, M. Wang, Liquefaction response of loose gassy marine sand sediments under cyclic loading. Bul. Eng. Geol. Env. 77.3, pp. 963-976 (2018)

27. G. C. Sills, S. J. Wheeler, S. D. Thomas, J. N. Gardner, Behaviour of offshore soils containing gas bubbles. Géotechnique 41.2, pp. 227-241 (1991)

28. S. J. Wheeler, A conceptual model for soils containing gas bubbles. Géotechnique 38.3, pp. 389-397 (1988)

29. S. D. Thomas, The consolidation behaviour of gassy soil. PhD Thesis, Univ. Oxford (1987)

30. G. C Sills, R. Gonzalez, Consolidation of naturally gassy soft soil. Géotechnique 51.7, pp. 629-639 (2001)

31. N. Sultan, V. de Gennaro, A. Puech, Mechanical behaviour of gas-charged marine plastic sediments. Géotechnique 62.9, pp. 751-766 (2012)

32. S. J. Wheeler, The undrained shear strength of soils containing gas bubbles. Géotechnique 38.3, pp. 399-413 (1988)

33. D. M. Wood, Soil Behaviour and Critical State Soil Mechanics (1990)

34. N. Sultan, S. Garziglia, Mechanical behaviour of gas-charged fine sediments: model formulation and calibration. Géotechnique 64.11, pp. 851-864 (2014)

35. Z. Gao, Y. Hong, Constitutive modelling of gassy clay. E3S Web Conf. 92, IS-Glasgow (2019)

36. Y, L. Hong, Wang, B. Yang, Undrained Shear Behaviour of Gassy Clay with Varying Initial Pore Water Pressures. Proc. China-Eur. Conf. Geotech. Eng. pp. 524-528 (2018) 